\title{
Size Determination by the Filtration Method of the Reproductive Elements of Group A Streptococcal L-Forms
}

\author{
By C. P. A. vaN BOVEN,* HENRIETTE L. ENSERING \\ AND W. HIJMANS \\ Institute for Rheumatism Research, University Hospital, Leiden, The Netherlands
}

(Accepted for publication 15 February 1968)

SUMMAR Y

The ability of the L-form of two strains of group A streptococci to pass filters was assessed by several methods. From a comparison of the results, and taking into account the plasticity of the $\mathrm{L}$ elements, it is concluded that the size of the reproductive elements of the L-form of the group A streptococcal strains investigated probably lies between $0.45 \mu$ and $0.65 \mu$. The passage of the elements through filters with pores measuring $0.45 \mu$ or less in diameter may be explained by the ease with which the elements are deformed. The variation between the results obtained with different filtration methods can be attributed to differences in experimental conditions which affect the degree of deformation.

\section{INTRODUCTION}

Because filterability is one of the characteristics of the L-forms of bacteria, considerable interest has been shown in the size of these filterable elements. Their capacity to pass filters which retain the bacterial form was first demonstrated by Klieneberger-Nobel ( 1949) for the L-form of Streptobacillus moniliformis, and was later confirmed for the L-forms of other bacteria (Carrère, Roux \& Mandin, 1954; Tulasne \& Lavillaureix, 1958). Several authors have examined the size of these filterable elements of the L-form of various bacteria by the filtration method (Klieneberger-Nobel, 1949, 1956, 1962; Wittler, 1954; Kellenberger, Liebermeister \& Bonifas, I956; Rada, I959; Williams, 1963). The results of these experiments give values between $0.175 \mu$ and $0.35 \mu$ for the diameter of the smallest reproductive elements, although Williams (1963) could not demonstrate passage of the L-form of staphylococci through filters with pore size below $0.7 \mu$.

The ability to grow through filters was investigated for the L-form of Proteus (Silberstein, 1953; Tulasne \& Lavillaureix, I958) and the L-form of staphylococci (Williams, 1963; Molander, Weinberger \& Kagan, I965). The smallest pore sizes through which the staphylococcal L-form grew are reported as $0.05 \mu$ by Molander et al. (I965) and $0.7 \mu$ by Williams (I963). The Proteus L-form penetrated filters with pore sizes down to $0.1-0.2 \mu$ (Tulasne \& Lavillaureix, 1958), and $0.75 \mu-0.50 \mu$ (Silberstein, I953). The same variation is shown by the results of the filtration experiments performed with the L-form of group A streptococci. The smallest pore sizes of the filters passed in the filtration method were reported as $0.45 \mu$ (Panos, Barkulis \& Hayashi, 1960; Mortimer,

\footnotetext{
* Present address: Laboratory of Microbiology, University of Utrecht, The Netherlands.
} 
I965) and $0.22 \mu$ (Coussons \& Cole, I968), whereas growth through filters has been reported for pore sizes down to $0 \cdot 10 \mu$ (Dienes \& Madoff, 1966; Coussons \& Cole, I968).

A possible explanation for the discrepancy between the results may be differences in the methods used. The ability of the L-form of two strains of group A streptococci to pass filters has therefore been assessed by various methods in a comparative study. Filtration of L-form broth cultures through a series of Millipore membrane filters was done according to the principles laid down by Elford (1938). The capacity for growing through filters was determined in solid and liquid media. Another source of differences, as pointed out by Roux (1960) and Weibull \& Lundin (I962), may be the plasticity of the L elements, which makes the filtration method liable to give variable results when applied to the size determination of these deformable particles. The results obtained in the present work support this view.

\section{METHODS}

Organisms and cultivation. Two strains of group A, $\beta$-haemolytic streptococci were used. Both strains had originally been obtained from Dr L. Dienes (Boston, Mass., U.S.A.). They belonged to the serological types $\mathrm{I} 9$ and $\mathrm{I} 2$, and were designated GL-8 and AED, respectively. The L-forms had been derived from the parent strains by the penicillin gradient technique according to Sharp (1954). The L-forms were cultivated in a medium composed of $2.8 \%(\mathrm{w} / \mathrm{v})$ Brucella Broth (Albimi Laboratories, Inc., Brooklyn 2, New York), sodium chloride $0.56 \mathrm{M}$ and sodium penicillin to 1000 i.u. $/ \mathrm{ml}$. The medium was solidified with I \% (w/v) agar (Special Agar Noble, Difco Laboratories, Inc., Detroit, U.S.A.). The L-forms of both strains had been subcultured in brucella broth medium over I00-1 50 consecutive transfers. The cultures were incubated at $37^{\circ}$. Viable counts, expressed as the number of colony-forming units (c.f.u.)/ml., were determined by the pour-plate technique. The streptococci were grown in ToddHewitt Broth (Difco). Nutrient Broth (Difco) was used for the cultivation of the Serratia marcescens.

Influenza A virus was grown on fertile hen's eggs, harvested, and purified by adsorbtion and elution from erythrocytes. The titre of the saline suspension was determined by the haemagglutination method.

Filter and filter apparatus. Standard Millipore filter membranes (Millipore Filter Corporation, Bedford, Mass., U.S.A.) of the following types and mean pore sizes were used: SM $(5.0 \mu)$, SS $(3.0 \mu)$, RA $(1 \cdot 2 \mu)$, AA $(0.8 \mu)$, DA $(0.65 \mu)$, HA $(0.45 \mu)$, PH $(0.30 \mu)$, GS $(0.22 \mu)$, VC $(0.10 \mu), \operatorname{VM}(0.05 \mu)$ and VF $(0.01 \mu)$.

Two types of filter holder were used. (i) The Swinny Hypodermic Adapter (Millipore Cat. No. XX 30012 o0) with filters of diam. I $3 \mathrm{~mm}$., filtration surface $0.8 \mathrm{~cm} .{ }^{2}$. (ii) The Stainless Pressure Filter Holder (Millipore Cat. No. XX 40047 00), with filters 47 mm. diam., filtration surface $\mathrm{I} \cdot 3 \mathrm{~cm} .^{2}$. The volumes filtered through the two types of filter holder were $10-15 \mathrm{ml}$. and $80-100 \mathrm{ml}$, respectively. The filters, sterilized when necessary with ethylene oxide, and the autoclaved filter holders were assembled aseptically. The Swinny adapter was attached on one side to a sterile $10 \mathrm{ml}$. standard hypodermic syringe; the other side of the filter holder was provided with a sterile needle to collect the filtrate. After removal of the plunger, the sample was pipetted into the syringe and the entire assembly was fitted by means of rubber rings into a cylindrical glass bell. 
The glass bell was then connected by rubber tubing to a pressure vessel. Six glass bells could be connected to the pressure vessel, permitting six samples to be run simultaneously under identical experimental conditions. The pressure, supplied by a pressure pump, was regulated and controlled by the stopcocks and manometer of the pressure vessel. The stainless pressure filter holder was connected to a nitrogen cylinder, the pressure being regulated by the reducing valve.

Filtration. The experiments were done at room temperature $\left(20-22^{\circ}\right)$, under a positive pressure of $0.2-0.3 \mathrm{~kg} . / \mathrm{cm} .{ }^{2}$. A few experiments performed under negative pressure gave essentially the same results.

Homogeneous suspensions of L-form cultures were prepared by vigorous shaking and subsequent centrifugation at $1000 \mathrm{~g}$ for $20 \mathrm{~min}$. at $4^{\circ}$. The resulting supernatant fluid, containing about $10^{6}$ to $10^{7}$ colony forming units per ml. (c.f.u./ml.), to be further referred to as 'L-form suspension', was used in the experiments. At the start of each experiment the number of c.f.u./ml. of the suspensions was assayed. Portions of the suspensions held at room temperature during the experiments showed no appreciable change in the number of c.f.u. Immediately after collection, the number of c.f.u./ml. was determined in the filtrates, which were collected either totally or in a number of fractions. In the latter case the fraction containing the highest number of c.f.u./ml. (the maximum concentration) was regarded as representative of the filtration through that filter. Further details are given under Results.

The Serratia marcescens cultures, incubated for 4-6 hr, were washed and resuspended in the brucella broth medium. Before suspension in the same medium, the streptococcal cultures were treated 5 times for periods of I min. in a ultrasonic disintegrator (MSE, Model $60 \mathrm{~W}, 60 \mathrm{kcyc} . / \mathrm{sec}$.) to disrupt the chains.

Growth through filters. Circular pieces of Millipore membrane filters of diam. $0.7 \mathrm{~cm}$. were placed on agar plates and the filter surfaces inoculated with a drop of L-form culture. The plates were then sealed with paraffin, incubated for 7 days, and the filters then removed and the plates inspected for colonies. Control experiments were made with the streptococcal strains GL-8 and AED. For the experiments in liquid medium, the Bellco Parabiotic Chamber (Bellco Glass Inc., Vineland, New Jersey, U.S.A.) was used, filters of various porosities being placed between the compartments. Both compartments were filled with the broth, and one side was inoculated with L-form growth. The uninoculated side was subcultured daily during a 3-day incubation period. Experiments with Serratia marcescens and the streptococci GL- 8 and AED served as controls.

\section{RESULTS}

\section{Filtration experiments}

To establish the relationship between filter pore size and particle diameter, the Millipore membrane filters were tested with suspensions of Serratia marcescens (size $0.5 \mu \times 0.5$ to I $\cdot 0 \mu$, Bergey's Manual, I957) and influenza A virus (size $0.08-0 . \mathrm{I} \mu$; Topley \& Wilson's Principles, 1964). The $10 \mathrm{ml}$. samples of $S$. marcescens suspensions in brucella salt medium were filtered simultaneously through filters of various pore size, employing the Swinny adapter filter holders. The filtrates were collected in portions of $2.5 \mathrm{ml}$. The number of c.f.u./ml. of the fraction with the highest concentration was recorded. Influenza A virus was suspended in saline, samples (Io ml.) were filtered and collected. With the exception of the saline suspending medium, the experi- 
mental conditions were the same as used in the experiments with the L-form suspensions. The results are given in Tables $I$ and 2.

For both Serratia marcescens and the influenza A virus, a close relationship was found between the pore diameter of the filter membrane just able to retain completely all the dispersed particles, the limiting pore diameter (l.p.d.), and the smallest size of these particles, indicating a direct relation between the 1.p.d. and the size of the particles. This was confirmed by the results obtained with the GL- 8 and AED strains of group A streptococci (size 0.6-I·0 $\mu$, Bergey's Manual, 1957). For both strains an 1.p.d. of $0.65 \mu$ was found.

\section{Table I. Filtration of Serratia marcescens through Millipore membrane filters}

Samples ( $10 \mathrm{ml}$.) of $4 \mathrm{hr}$ cultures resuspended in brucella broth salt medium, were filtered simultaneously through membrane filters of the indicated pore sizes. Filtrates were collected in $4 \times 2.5 \mathrm{ml}$. fractions. The number of c.f.u. $* / \mathrm{ml}$. of the fraction containing the maximum concentration is recorded as log. no. c.f.u./ml. and, in parentheses, as \% of the original number (the maximum relative concentration).

\begin{tabular}{|c|c|c|c|c|c|}
\hline & $\begin{array}{c}\text { Expt. I } \\
\text { Log }\end{array}$ & $\begin{array}{l}\text { Expt. } 2 \\
\text { c.f.u./ml. }\end{array}$ & $\begin{array}{l}\text { Expt. } 3 \\
\text { original }\end{array}$ & $\begin{array}{c}\text { Expt. } 4 \\
\text { suspension }\end{array}$ & \multirow{3}{*}{$\begin{array}{c}\text { Average } \\
\text { maximum } \\
\text { relative con- } \\
\text { centration }\end{array}$} \\
\hline & $7 \cdot 30$ & $5 \cdot 95$ & 6.95 & $5 \cdot 90$ & \\
\hline $\begin{array}{l}\text { Filter pore } \\
\text { size }(\mathrm{m} \mu)\end{array}$ & \multicolumn{4}{|c|}{ Filtrates (log c.f.u./ml.) } & \\
\hline 3000 & $5 \cdot 48(1 \cdot 5)$ & n.t. $\dagger$ & $4.48(0.3)$ & n.t. & 0.9 \\
\hline 1200 & $4 \cdot 48(0 \cdot 2)$ & $3.30(0.2)$ & $3 \cdot 30(0 \cdot 2)$ & $3.77(0.8)$ & 0.3 \\
\hline 800 & $4.30(0.2)$ & n.t. & $3.84(0.08)$ & $3.69(0.6)$ & 0.2 \\
\hline 650 & n.t. & $2.30(0.02)$ & $3.00(0.01)$ & $1.95(0.01)$ & 0.01 \\
\hline 450 & $o(0)$ & $o(0)$ & $O(0)$ & o (o) & 0 \\
\hline
\end{tabular}

Table 2. Filtration of influenza A virus through Millipore membrane filters

Samples ( $10 \mathrm{ml}$.) of saline suspensions were filtered through membrane filters of the indicated pore sizes. Virus titre assayed by the haemagglutination (h.a.) method

\begin{tabular}{|c|c|c|}
\hline & \multicolumn{2}{|c|}{$\begin{array}{l}\text { Expt. I } \\
\text { Expt. } 2 \\
\text { h.a. titre of the original suspension }\end{array}$} \\
\hline & $5 \mathrm{I} 2$ & 64 \\
\hline Filter pore & \multicolumn{2}{|c|}{ h.a. titre of the filtrates } \\
\hline 3000 & n.t.* & 64 \\
\hline 220 & 256 & 64 \\
\hline 100 & 4 & $<4$ \\
\hline 50 & $<4$ & $<4$ \\
\hline 10 & $<4$ & $<4$ \\
\hline
\end{tabular}

Simultaneous filtration of L-form suspensions. The L-form suspensions were prepared from $\mathrm{I} 8-24 \mathrm{hr}$ cultures. In each experiment several $\mathrm{IO} \mathrm{ml}$. samples of one L-form suspension were passed simultaneously through filter membranes of different porosities in Swinny adapter filter holders, and the filtrates collected in $2.5 \mathrm{ml}$. fractions. Table 3 
shows the number of c.f.u./ml. contained in the fraction with the maximum concentration. These data indicate an l.p.d. of $0.30 \mu$ for the $\mathrm{L}$ elements.

Sequential filtration of $L$ form suspensions. To rule out the possibility that obstruction of the filter pores could result in too high value of the l.p.d., a further series of experiments was made. L-form suspensions were prepared from I 8-24 hr. cultures, and one sample of each suspension was filtered successively through filters with progressively

\section{Table 3. Simultaneous filtration through Millipore membrane filters of the $L$-forms of 2 strains of group $A$ streptococci}

Samples ( $10 \mathrm{ml}$.) of L-form suspensions prepared from $\mathrm{I} 8$ to $24 \mathrm{hr} \mathrm{L}$-form broth cultures, were filtered simultaneously through membrane filters of the indicated pore sizes. Filtrates were collected in $4 \times 2.5 \mathrm{ml}$. fractions. The number of c.f.u. $* / \mathrm{ml}$. of the fraction containing the maximal concentration is recorded as log. no. c.f.u./ml. and, in parentheses, as $\%$ of the original number (maximum relative concentration).

\begin{tabular}{|c|c|c|c|c|c|}
\hline \multirow{4}{*}{$\begin{array}{l}\text { Filter } \\
\text { pore size } \\
(\mathrm{m} \mu)\end{array}$} & \multicolumn{4}{|c|}{ Strain of streptococcus } & \multirow{4}{*}{$\begin{array}{l}\text { Average } \\
\text { maximum } \\
\text { relative con- } \\
\text { centration } \\
(\%)\end{array}$} \\
\hline & \multicolumn{4}{|c|}{ Log c.f.u./ml. original suspension } & \\
\hline & $6 \cdot 00$ & $6 \cdot 00$ & $7 \cdot 30$ & $6 \cdot 00$ & \\
\hline & \multicolumn{4}{|c|}{ Filtrates (log c.f.u./ml.) } & \\
\hline 5000 & n.t. $\dagger$ & $4.95(9)$ & $6 \cdot 30(\mathrm{IO})$ & $5.00(10)$ & 10 \\
\hline 800 & n.t. & $5 \cdot 30(\mathrm{I} 8)$ & $6.00(7)$ & $5 \cdot 00(\mathrm{IO})$ & I 2 \\
\hline 650 & $5 \cdot 20(16)$ & n.t. & $6 \cdot 44(\mathrm{I} 4)$ & $4 \cdot 84(7)$ & I 2 \\
\hline 450 & $2 \cdot 00(0.05)$ & $1.47(0.003)$ & $0(0)$ & $\mathrm{I} \cdot 00(0.01)$ & 0.02 \\
\hline 300 & n.t. & $0(0)$ & $0(0)$ & $o(0)$ & 0 \\
\hline 220 & $o(0)$ & $0(0)$ & $o(0)$ & $o(0)$ & 0 \\
\hline
\end{tabular}

Table 4. Sequential filtration through Millipore membrane filters of the L-forms of 2 strains of group A streptococci

Samples ( $10 \mathrm{ml}$.) of L-form suspensions prepared from 18 to $24 \mathrm{hr}$ L-form broth cultures, were filtered successively through membrane filters of decreasing porosity. After each passage, $\mathrm{I} \mathrm{ml}$. of the filtrate was inoculated into broth. The absence $(-)$ or the occurrence $(+)$ of growth after 5-day incubation is indicated.

\begin{tabular}{|c|c|c|c|c|c|c|}
\hline & & $L-8$ & \multicolumn{4}{|c|}{ Strain AED } \\
\hline & \multicolumn{6}{|c|}{ Growth obtained from the original suspensions } \\
\hline & + & + & + & + & + & + \\
\hline Filter pore & \multicolumn{6}{|c|}{ Growth obtained from the filtrates } \\
\hline 1200 & + & n.t.* & + & n.t. & n.t. & + \\
\hline 800 & + & + & n.t. & + & + & n.t. \\
\hline 650 & + & + & + & + & n.t. & + \\
\hline 450 & + & + & + & + & + & + \\
\hline 300 & n.t. & - & - & - & + & - \\
\hline 220 & - & - & - & - & - & - \\
\hline
\end{tabular}




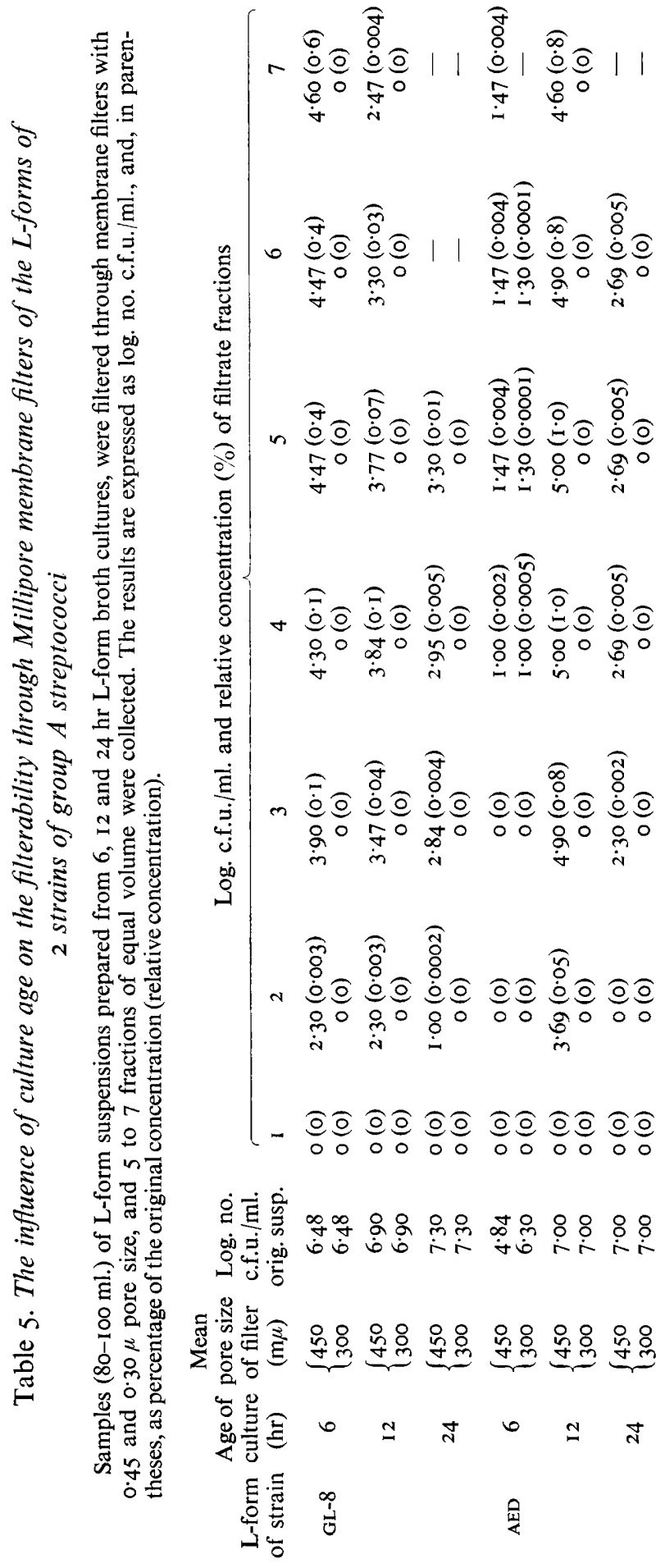


smaller pore size. The experiments were started with IO-I $5 \mathrm{ml}$. samples, and after each passage $1 \mathrm{ml}$. of the filtrate was inoculated into broth. These cultures were incubated for 5 days, and growth assessed from daily subcultures on agar plates. As can be seen from Table 4, essentially the same results were obtained. With the exception of one experiment, the $0 \cdot 30 \mu$ filtrate remained negative.

Culture age and filterability of L-form suspensions. To assess the influence of the age of the culture on filterability, especially through the limiting filter, L-form suspensions were prepared from cultures incubated for 6 , I2, and $24 \mathrm{hr}$. To study the effects of absorption and clogging on the filtration process, volumes of $80-100 \mathrm{ml}$. were filtered through $0.30 \mu$ and $0.45 \mu$ filters in stainless pressure filter holders. For the 6 or 7 filtrate fractions of equal volume thus obtained, the number of c.f.u. $/ \mathrm{ml}$. was determined separately. The results (Table 5) showed that although the L-form suspensions prepared from cultures incubated for 6 and $12 \mathrm{hr}$ seemed to pass a little more readily, the age of the culture did not influence the filtration results with respect to the size of the limiting pore diameter. Except in one experiment (see Table 5) in which a small percentage of the reproductive elements passed it, the $0.30 \mu$ filter retained the $\mathrm{L}$ elements.

The first filtrate fractions of the $0.45 \mu$ filter were always negative, the following two fractions gave an increasing number of c.f.u./ml. The maximum number of c.f.u. $/ \mathrm{ml}$. was found in fractions no. 4 or 5 , and remained nearly constant in the following fractions. This result indicates a slow and difficult passage of the reproductive elements through the filter pores. An appreciable effect of clogging of the filter pores, which would have been shown by a decrease of the number c.f.u./ml., was not observed, however.

\section{Growth through membrane filters}

Experiments on agar plates. The L-forms of the two streptococcal strains inoculated on Millipore membrane filters of various pore sizes placed on agar plates, grew through filters with pore sizes of $0.22 \mu$ or larger. The passage through the filters was shown by the development of colonies underneath the filters (Pl. I). Although growth occurred on top of the 0 . Io $\mu$ filter, penetration of this filter was not observed during the incubation period. The control experiments with the GL- 8 and AED streptococcal parent strains showed that, although abundant growth occurred on top of the filters, the bacterial form did not grow through any of the filters.

Experiments in broth medium. The L-form of both streptococcal strains grew through the filter of $0.30 \mu$ pore size. Irregular results were obtained with the $0.22 \mu$ filter.

The Serratia marcescens and the streptococcal parent strains used in the control experiments passed through the $0.45 \mu$ and the $0.65 \mu$ filters, respectively. The $S$. marcescens was completely retained by the $0.30 \mu$ and the streptococcus by the $0.45 \mu$ filter.

\section{DISCUSSION}

Lederberg \& St Clair (1958), Roux (I960), and Weibull \& Lundin (1962) have pointed out that the plasticity of the L-form elements may be a factor which determines the filterability of the bacterial L-forms. The deformability of the L elements should therefore be taken into account in the interpretation of the results of filtration experiments. In general, the results obtained in the present study with the L-forms of the GL-8 and AED strain of group A streptococci are in agreement with the results reported in the literature (Panos, Barkulis \& Hayashi, I960; Mortimer, 1965; Dienes \& Madoff, I966; 
Coussons \& Cole, 1968). However, the question of the significance of the filterability with respect to the size of the filterable and reproductive elements remains.

In these experiments the percentage of reproductive elements passing the filter with a pore size of $0.45 \mu$ varied between I $\%$ and $0.001 \%$ or even less. A low filtration recovery after filtration of bacterial L-forms through filters with pore sizes of $0.6 \mu$ or smaller has been reported (Klieneberger-Nobel, 1949, 1962; Rada, I959; Kellenberger et al. 1956; Panos et al. 1960). The low filtration recovery cannot be solely explained by mechanical obstruction of the filter pores and adsorption on to the filter surface. The similar results obtained in the serial and sequential filtration experiments, and the absence of a decrease in the number of viable elements passing a single filter during filtration indicated that, under the experimental conditions used, mechanical blocking of the filter pores did not influence the results to a significant degree. In both the control experiments and the experiments performed with the streptococcal L-forms, on the other hand, a strong adsorption of elements on to the filters occurred. This is demonstrated by the reduction in viable count of the suspensions after passage through filters with pore sizes many times larger than the diameter of the suspended particles. This retention, which is due to electrostatic charges (see Millipore Application Data Manual, 1963, Millipore Filtration Corp.. Bedford, Mass. U.S.A.), did not however, influence the relationship between the particle diameter and the size of the limiting pore diameter, as indicated by the control experiments. Furthermore, the number of reproductive L-form elements passing the filters remained nearly constant up to the $0.65 \mu$ filter, but showed a sharp decrease at the $0.45 \mu$ filter. The filtration recoveries obtained with the control suspensions of Serratia marcescens and influenza A virus, to the contrary, gradually decreased with decreasing filter pore size. This suggests that either the L-forms constitute a homogeneous population of $\mathrm{L}$ elements with respect to size or that passage is effected by means of deformation. In view of the pleomorphic character of the bacterial L-form, the latter explanation seems the more likely. The maximal degree of deformation which is still compatible with viability occurs with filters of $0.45 \mu$ porosity.

The low filtration recovery obtained with this filter can be explained by the assumption that only a few elements are capable to pass these filters. In addition, the results show that the filterability of the streptococcal L-forms was not influenced by the age of the L-form cultures.

Penetration of the $0.30 \mu$ and $0.22 \mu$ filters occurred in the experiments in which the streptococcal L-forms grew through the filters. These filters were not passed by reproductive elements in the filtration experiments. The divergence between the results of the two methods, which is also found in the literature, is perhaps also best explained by the assumption that the pliable L-form elements are able to adjust to and pass through these smaller filter pores by deformation. Apparently, a higher degree of deformation of the L-form elements can be achieved in the slow process of penetration by growth than under the conditions prevailing in the filtration experiments.

The present results suggest that the plasticity of the streptococcal L-form elements is indeed a factor determining the filterability of the L-form. Consequently, a conclusion about the size of the smallest reproductive elements is difficult to reach. The principles governing size determination by the filtration method, i.e. the relationship between limiting pore diameter and particle size (Elford, 1938), are based on the concept of a rigid particle. These principles should therefore not be applied to the results obtained with L-form elements because of their pliability. 
The sharp decrease in the number of reproductive elements passing the $0.45 \mu$ filter as compared to the $0.65 \mu$ filter indicates, however, that in all likelihood the size of the smallest reproductive elements of the L-form of the two group A streptococcal strains used in this study lies between these values.

The authors are indebted to Dr N. Mazurel of the Department of Internal Medicine, Leiden University Hospital, who kindly supplied and titrated the influenza A virus used in this study.

\section{REFERENCES}

Bergey's Manual of Determinative Bacteriology (1957). 7th ed. Ed. by R. S. Breed, E. G. D. Murray \& N. R. Smith. Baltimore: Williams and Wilkins.

Carrère, L., Roux, J. \& Mandin, J. (I954). A propos du cycle L des bactéries: obtention de formes naines, viables et filtrables, en milieu liquide. C. r. Séanc. Soc. Biol. $\mathbf{1 4 8 , 2 0 5 0 .}$

Coussons, R. T. \& Cole, R. M. (I968). The size and replicative capacities of small bodies of group A streptococcal L-forms. In The Present Status of Research on Group A Streptococcus. Ed. R. Caravano. Amsterdam: Excerpta Medica Foundation.

Dienes, L. \& MADOFF, S. (1966). Development and growth of L-forms of bacteria and PPLO on membrane filters. Proc. Soc. exp. Biol. Med. 121, 334.

ELFORD, W. J. (1938). The size of viruses and bacteriophages, and methods for their determination. In Handbuch der Virusforschung. Ed. by R. Doerr \& C. Hallauer. Wien: Verlag von Julius Springer.

Kellenberger, E., Liebermeister, K. \& Bonifas, V. (i956). Studien zur L-Form der Bakterien. II. Dimension und Filtrierbarkeit der globulären Form. Z. Naturf. II b, 206.

KLIENEBerger-Nobel, E. (I949). On Streptobacillus moniliformis and the filtrability of its L form. J. Hyg., Camb. 47, 393.

KLIENEBERGER-Nobel, E. (1956). Über die Wesensverschiedenheit der peripneumonie-ähnlichen Organismen und der L-phase der Bakterien. Zentbl. Bakt. ParasitKde. Abt I. 165, 329.

KLIENEBerger-Nobel, E. (1962). Pleuropneumonia-like Organisms (PPLO) Mycoplasmataceae. London and New York: Academic Press.

Lederberg, J. \& St Clair, J. (1958). Protoplasts and L-type growth of Escherichia coli. J. Bact. 75, 143.

Molander, C. W., Weinberger, H. J. \& Kagan, B. M. (1965). Growth of staphylococcal L-forms on and through membrane discs of various pore sizes. J. Bact. 89, 907.

Mortimer, E. A. (1965). Production of L-forms of group A streptococci in mice. Proc. Soc. exp. Biol. Med. II9, 159 .

Panos, C., Barkulis, S. S. \& Hayashi, J. A. (1960). Streptococcal L-forms. III. Effects of sonic treatment on viability. J. Bact. 8o, 336.

RadA, B. (1959). Filtrierbarkeit der L-phase und der globulären Form der Bakterien. Zentbl. Bakt. ParasitKde. Abt I. 176, 85.

Roux, J. (1960). La multiplication des formes L. Annls Inst. Pasteur, Paris 99, 286.

SHARP, J. T. (1954). L colonies from hemolytic streptococci: New technic in the study of L-forms of bacteria. Proc. Soc. exp. Biol. Med. 87, 94.

Silberstein, J. K. (1953). Observations on the L-forms of Proteus and Salmonella. Schweiz. Z. allg. Path. Bakt. 16, 739.

Tulasne, R. \& Lavillaureix, J. (1958). Filtration et ultrafiltration d'une souche de forme L fixée. C. r. hebd. Séanc. Acad. Sci., Paris, 246, 2396.

Weibull, C. \& Lundin, B-M. (1962). Growth of elements of various sizes found in cultures of a stable Proteus L-form. J. gen. Microbiol. 27, 24I.

WiLliams, R. E. O. (1963). L-forms of Staphylococcus aureus. J. gen. Microbiol. 33, 325.

Topley and Wilson's Principles of Bacteriology and Immunity. (1964). 5th ed. Ed. by G. S. Wilson and A. A. Miles. Chap. 73. London: Edward Arnold (Publishers) Ltd.

Wittler, R. G. (1954). A filterable stage isolated from the L-form of Haemophilus pertussis. Bact. Proc. p. $4 \mathrm{I}$. 


\section{EXPLANATION OF PLATE}

Millipore membrane filter discs were placed on the surface of an agar plate and inoculated on top with the liquid growth of the L-form of the AED strain of group A streptococci. The photograph was taken after 5-days incubation, after removal of the filter discs. Penetration of the filters is shown by the development of $\mathrm{L}$-form colonies in the agar underneath the filters. The numbered labels indicate the pore size $(\mu)$ of the filters employed. $\times I \cdot 3$. 
Journal of General Microbiology, Vol. 52, No. 3

Plate I

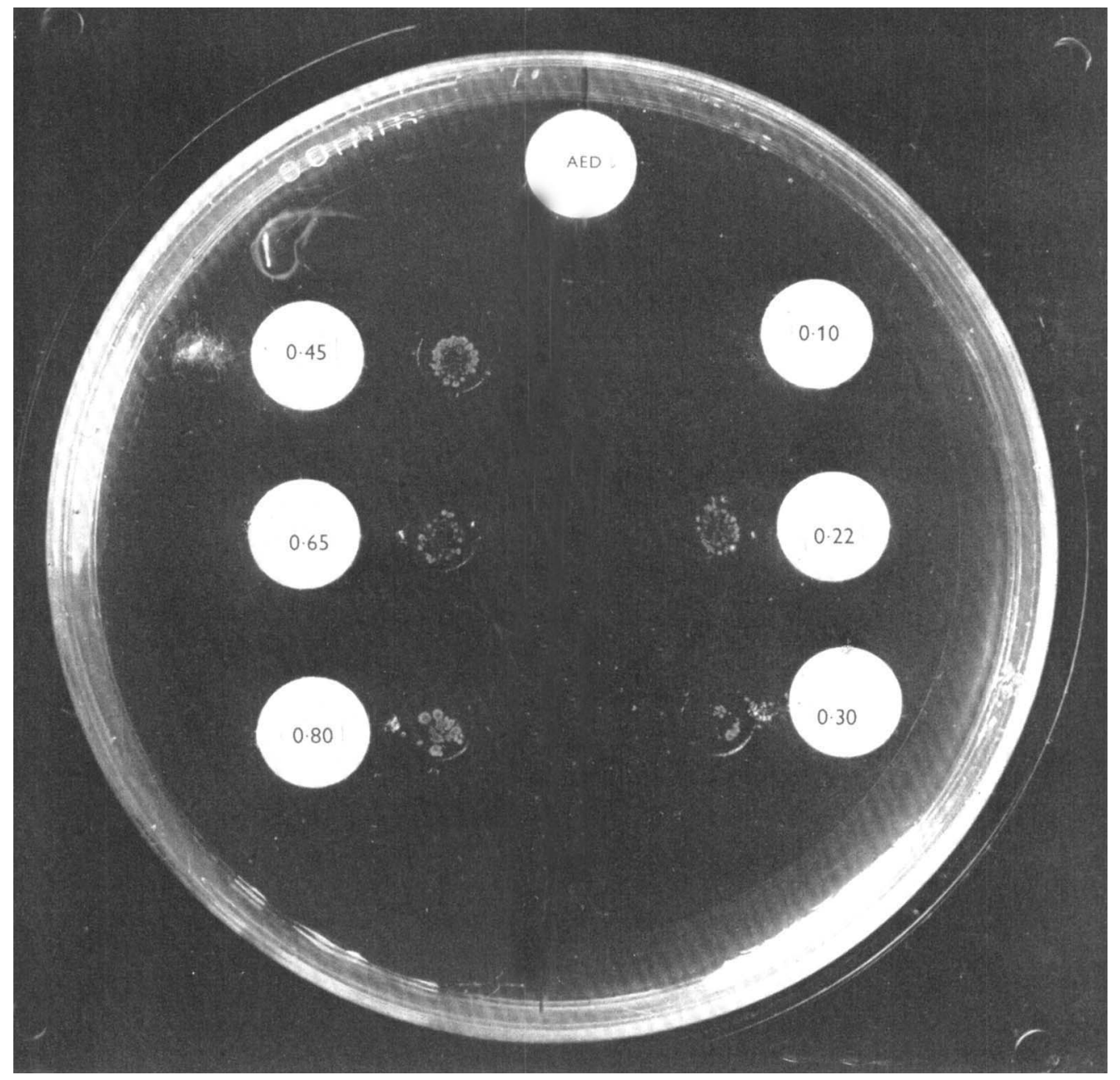

C. P. A. VAN BOVEN, H. L. ENSERING AND W. HIJMANS

(Facing p. 412) 